
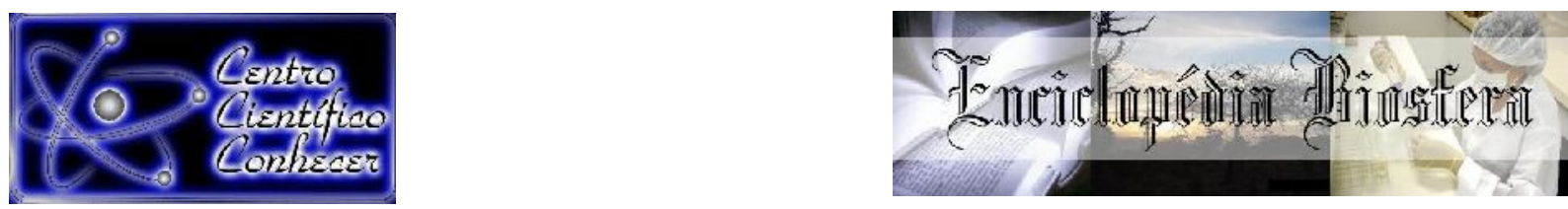

\title{
ASPECTOS MORFOLÓGICOS DA GENITÁLIA EXTERNA DE TOUROS ASSOCIADOS À IMPOTENNCIA COEUNDI
}

\author{
Vantuil Moreira de Freitas ${ }^{1}$, Rogério Elias Rabelo ${ }^{2}$, Bruno Moraes Assis ${ }^{3}$, Paulo José \\ Basto Queiroz ${ }^{4}$, Valcinir Aloísio Scalla Vulcani ${ }^{5}$.
}

${ }^{1}$ Docente do Centro Universitário de Mineiros - UNIFIMES - Mineiros, GO

${ }^{2}$ Docente - APRIMORY VET - Cursos e Consultoria Especializada - Jataí, GO.

${ }^{3}$ Docente - Centro Universitário Una Unidade de Jataí, GO.

${ }^{4}$ Docente da Escola de Veterinária e Zootecnia (EVZ) da Universidade Federal de Goiás (UFG) - Goiânia, GO.

${ }^{5}$ Docente - Universidade Federal de Jataí e PPGCA/EVZ - Universidade Federal de Goiás - Goiânia, GO.

E-mail: vantuil@unifimes.edu.br

\section{Recebido em: 15/08/2021 - Aprovado em: 15/09/2021 - Publicado em: 30/09/2021 \\ DOI: 10.18677/EnciBio_2021C7}

trabalho licenciado sob licença Creative Commons Attribution-NonCommercial-NoDerivatives 4.0 International License.

\section{RESUMO}

O touro é essencial para a realização de monta natural, que ainda é majoritária na pecuária brasileira, e para o melhoramento genético de seus descendentes. A genitália externa do touro é composta pelo prepúcio e pênis e tem como função vital a efetivação da cópula. No entanto, esses órgãos são vulneráveis e suscetíveis a lesões devido a variação das características morfológicas, tais como a largura do orifício do óstio prepucial, a pendulosidade e o comprimento da bainha prepucial. Portanto, o objetivo deste estudo foi realizar uma revisão de literatura dos aspectos morfológicos da genitália externa de touros associados à impotência coeundi devido às enfermidades prepuciais. O prepúcio ou bainha prepucial é constituído pelos folhetos prepuciais externo (FPE) e interno (FPI). O primeiro é formado por uma dobra de pele móvel aderida ao ventre do abdômen. O FPI ou mucosa prepucial caracteriza-se como um órgão tubular que aloja a parte livre do pênis. O óstio prepucial é o orifício de abertura através do qual ocorre a exteriorização do pênis. O prepúcio possui glândulas sebáceas que produzem uma secreção lipídica, que compõe o esmegma, e que é importante na higidez prepucial e peniana. Neste estudo utilizou-se a pesquisa básica como ferramenta de análise, segundo a nomenclatura anatômica veterinária, sobre aspectos da anatomia e morfologia da genitália externa, especificamente do prepúcio, da parte livre do pênis e das glândulas sebáceas prepuciais, pontos pouco citados pela literatura especializada, o que demonstra a importância dessa linha de estudo.

PALAVRAS-CHAVE: Esmegma; Glândula sebácea; Morfologia prepucial. 


\title{
MORPHOLOGICAL ASPECTS OF THE EXTERNAL GENITALIA OF BULLS ASSOCIATED WITH IMPOTENCE COEUNDI
}

\begin{abstract}
The bull is essential for the realization of natural breeding, which is still the majority in Brazilian livestock, and for the genetic improvement of its descendants. The bull's external genitalia are made up of the foreskin and penis and its vital function is to effect copulation. However, these organs are vulnerable and susceptible to injury due to variation in morphological characteristics, such as the width of the preputial ostium orifice, the pendulum and the length of the preputial sheath. Therefore, the aim of this study was to carry out a literature review of the morphological aspects of the external genitalia of bulls associated with coeundi impotence due to preputial diseases. The prepuce or preputial sheath consists of the external (LPE) and internal (LPI) preputial leaflets. The first is formed by a fold of mobile skin attached to the belly of the abdomen. The IPL or preputial mucosa is characterized as a tubular organ that houses the free part of the penis. The preputial ostium is the opening through which the exteriorization of the penis takes place. The foreskin has sebaceous glands that produce a lipid secretion, which makes up the smegma, and which is important in prepucial and penile health. In this study, basic research was used as an analysis tool, according to veterinary anatomical nomenclature, on aspects of the anatomy and morphology of the external genitalia, specifically the prepuce, the free part of the penis and the preputial sebaceous glands, points rarely mentioned in the specialized literature, which demonstrates the importance of this line of study.
\end{abstract}

KEYWORDS: Smegma; Sebaceous gland; Preputial morphology.

\section{INTRODUÇÃO}

O touro é importante na fase de cria porque é o animal melhorador do rebanho. Além disso, o sistema de cobertura das vacas por meio de monta natural, ainda é o mais utilizado na pecuária brasileira (BARUSELLI et al., 2019). O estudo das características anatômicas e morfológicas do aparelho reprodutor do macho bovino tem como objetivo criar parâmetros anatômicos entre raças, estabelecer critérios na seleção de touros e contribuir na prevenção de doenças reprodutivas. Essa é uma linha de pesquisa que vem ganhando força através da publicação de artigos relacionados à morfometria de diferentes órgãos do animal (MENDONÇA et al., 2019).

As características morfológicas da genitália externa relacionadas a determinadas raças, principalmente os touros zebuínos (Bos taurus indicus), podem explicar a incidência de enfermidades prepuciais e, consequentemente, o descarte de touros por falhas na cobertura ou Impotência coeundi causando prejuízos econômicos aos criatórios (VIU et al., 2002;RABELO et al., 2012).

Reforçando este princípio, um estudo retrospectivo realizado no Brasil, entre 1982 e 2007, avaliou 12.320 touros, dos quais 898 foram diagnosticados com afecções na genitália externa. Dos 898 reprodutores enfermos, 82,52 \% eram de raças zebuínas e a acropostite-fimose foi diagnosticada em $81 \%$ dos casos (RABELO et al., 2008). Em outro estudo epidemiológico realizado no período de 2007 a 2013, avaliaram 3.125 touros, dos quais 217 foram diagnosticados com afecções na genitália externa. Verificaram que 156 touros eram zebuínos (71,89\%) e a acropostite-fimose foi diagnosticada em 136 touros (RABELO et al., 2015). 
Algumas raças taurinas também são predispostas às lesões de prepúcio. Desrochers et al. (1995) examinaram 51 touros nos Estados Unidos com lesões prepuciais, e os animais das raças Bos taurus taurus (82,3\%) foram mais acometidos do que os touros das raças Bos taurus indicus (17,7\%). As raças mais afetadas foram Angus, Simental, Brangus e Hereford. Dentre estas, as raças Angus e Hereford têm predisposição ao desenvolvimento rudimentar e frágil do músculo retrator do prepúcio, resultando em fator de risco para a ocorrência de prolapso crônico da mucosa prepucial e, assim, maiores chances de traumatismos e lesões.

As perdas econômicas ocasionadas por enfermidades que comprometem a capacidade reprodutiva do touro são oriundas dos gastos com medicamentos, atendimento médico veterinário e descarte involuntário do reprodutor ou eventual morte do animal. Acrescente-se como um dos maiores gargalos, as perdas financeiras decorrentes de vacas não gestantes por causa do touro enfermo, que muitas vezes não são contabilizadas no sistema de produção (RABELO et al., 2017a, 2017b).

Até o momento, os estudos relacionados ao prepúcio e pênis de touros tiveram como ênfase a pesquisa aplicada às enfermidades da genitália externa. Entretanto, são poucas as pesquisas básicas sobre aspectos morfofuncionais e desenvolvimento destes órgãos reprodutivos (McGOWAN et al., 2018). Acrescente-se que os estudos sobre as glândulas sebáceas da pele são comuns nas áreas de dermatologia humana e veterinária, mas há poucas informações sobre as glândulas sebáceas prepuciais no touro e a produção de esmegma (HOOVER et al., 2020).

O esmegma é constituído de secreção lipídica e restos celulares das glândulas sebáceas prepuciais. Esta secreção é importante para a higidez prepucial e peniana e tem as funções de umedecer, lubrificar, evitar o ressecamento da mucosa e auxiliar na introdução do pênis na genitália feminina, além de ação antimicrobiana. No entanto, o acúmulo de esmegma no folheto prepucial interno (FPI) tem sido apontado como fator predisponente às doenças venéreas e prepuciais (RABELO et al., 2012).

Portanto, o objetivo deste estudo foi realizar uma revisão de literatura sobre aspectos da anatomia e morfologia da genitália externa, especificamente do prepúcio, da parte livre do pênis e das glândulas sebáceas prepuciais de touros associados à impotência coeundi devido às enfermidades prepuciais.

\section{Morfologia do pênis}

\section{DESENVOLVIMENTO}

O pênis, órgão copulador do macho, apresenta comprimento médio de um metro no touro adulto, e é dividido em três partes: a raiz, o corpo e a parte livre (Figura 1). A raiz tem a sua origem na inserção de dois ramos ou pilares dos músculos isquiocavernosos no arco isquiático, que é a porção caudal dos ossos ísquios, e termina no bulbo do pênis, onde ocorre a junção deste par de músculos. O corpo do pênis, tem o formato cilíndrico e longo, origina-se a partir do bulbo peniano, com a inserção da uretra peniana envolvida pelo músculo bulboesponjoso, e segue até a rafe do prepúcio ou inserção do FPI no pênis (BUDRAS; HABEL, 2003). 
FIGURA 1. Partes do pênis do bovino. PLP (parte livre do pênis), da glande até a rafe do prepúcio $\left({ }^{\star}\right)$; CP (corpo do pênis), da rafe do prepúcio, passando pela flexura sigmoide, até no bulbo do pênis ${ }^{* *}$; RP (raiz do pênis) constituída pelo par de músculos isquicavernosos $\left(^{* * *}\right)$. FS (flexura sigmoide ou $S$ peniano) e MRP (par de músculos retratores do pênis).

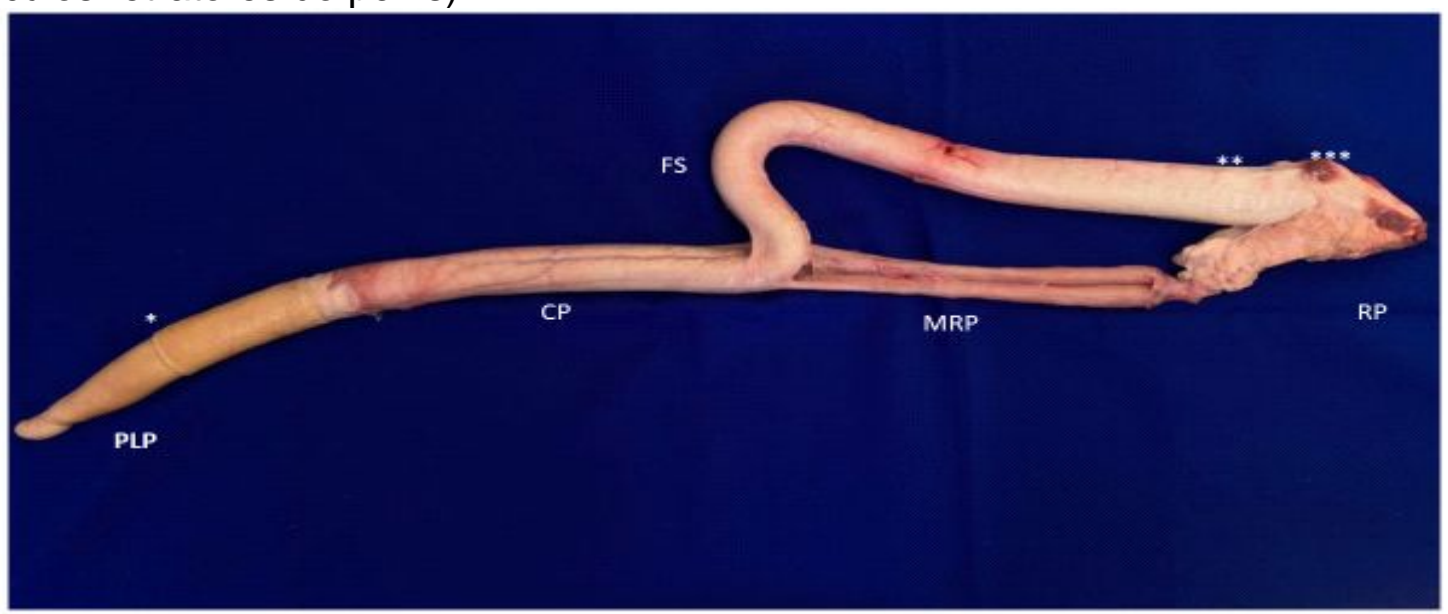

Fonte: Arquivo Pessoal.

Eurídes et al. (1998) avaliaram o comprimento do pênis de touros da raça Nelore com 36 a 48 meses de idade e encontraram o comprimento médio de 81,67 cm. Mendonça et al. (2012) constataram os comprimentos médios do pênis de $71,9 \mathrm{~cm}$ e $75,8 \mathrm{~cm}$, respectivamente, em touros Nelore e Gir com 30 a 38 meses de idade.

A parte livre do pênis (PLP) encontra-se dentro da cavidade prepucial, origina-se a partir da rafe do prepúcio ou inserção do FPI no pênis e inclui a glande na extremidade cranial ou ápice do pênis. O frênulo do prepúcio conecta a rafe do prepúcio à rafe do pênis (Figura 2). A rafe do pênis é uma crista oblíqua levemente torcida, responsável pela torção à esquerda ou sentido anti-horário da PLP durante a ejaculação (BUDRAS; HABEL, 2003; NABORS; LINFORD, 2015; SCHALLER, 2017).

FIGURA 2. Parte livre do pênis incluindo a glande até a rafe do prepúcio. A rafe do pênis é uma crista oblíqua levemente torcida. $O$ frênulo do prepúcio conecta a rafe do prepúcio à rafe do pênis.

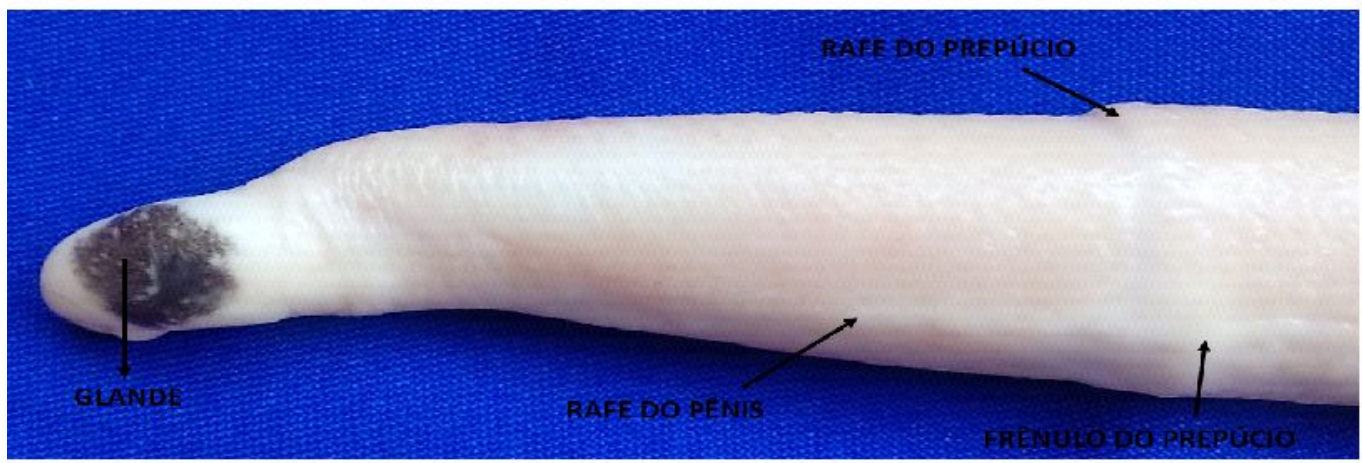

Fonte: Arquivo Pessoal. 
A glande encontra-se na extremidade da PLP e, portanto, faz parte da PLP (Figura 3). No estudo de Mendonça et al. (2012) os pesquisadores constataram que o comprimento da PLP $(9,0 \mathrm{~cm})$ de touros Nelore foi menor que a PLP $(9,8 \mathrm{~cm})$ de touros da raça Gir. Também a glande do Nelore $(3,1 \mathrm{~cm})$ foi menor que a glande do Gir $(3,3$ $\mathrm{cm}$ ). Entretanto, outros autores citam a glande com 10 a $12 \mathrm{~cm}$ de comprimento (DYCE et al., 1997; HAFEZ; HAFEZ, 2004). Esses autores podem ter considerado toda a PLP como glande, o que explica a ocorrência dessa discrepância.

FIGURA 3. Parte livre do pênis de touro Nelore com $9 \mathrm{~cm}$ comprimento. A seta indica a rafe do prepúcio (fixação do FPI ao corpo do pênis). * corpo do pênis envolto pelo FPI.

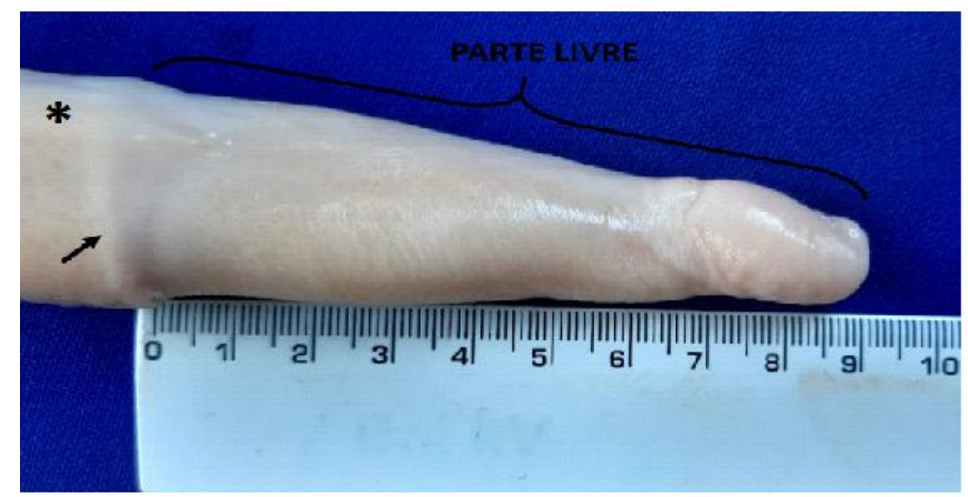

Fonte: Arquivo Pessoal.

A glande peniana está localizada no ápice da PLP (Figura 4). Possui extremidade pontiaguda e levemente torcida ou espiralada. Na porção ventral está a fossa da glande (Fossa glandis), onde localiza-se o discreto processo uretral e que culmina no óstio uretral externo ou via de eliminação do sêmen e urina. O colo da glande (Collum glandis) é uma constrição ou estreitamento da parte livre do pênis proximal à coroa da glande. O rebordo que contorna a base da glande é denominado de coroa da glande (Corona glandis) (BUDRAS; HABEL 2003; SCHALLER, 2017).

FIGURA 4. Glande do pênis do bovino. Em (A) vista dorsal da glande, (1) colo da glande; (2) coroa da glande; (3) ápice da glande e da PLP. Em (B) vista ventro lateral da glande, (4) processo uretral no óstio uretral externo; (5) fossa da glande.

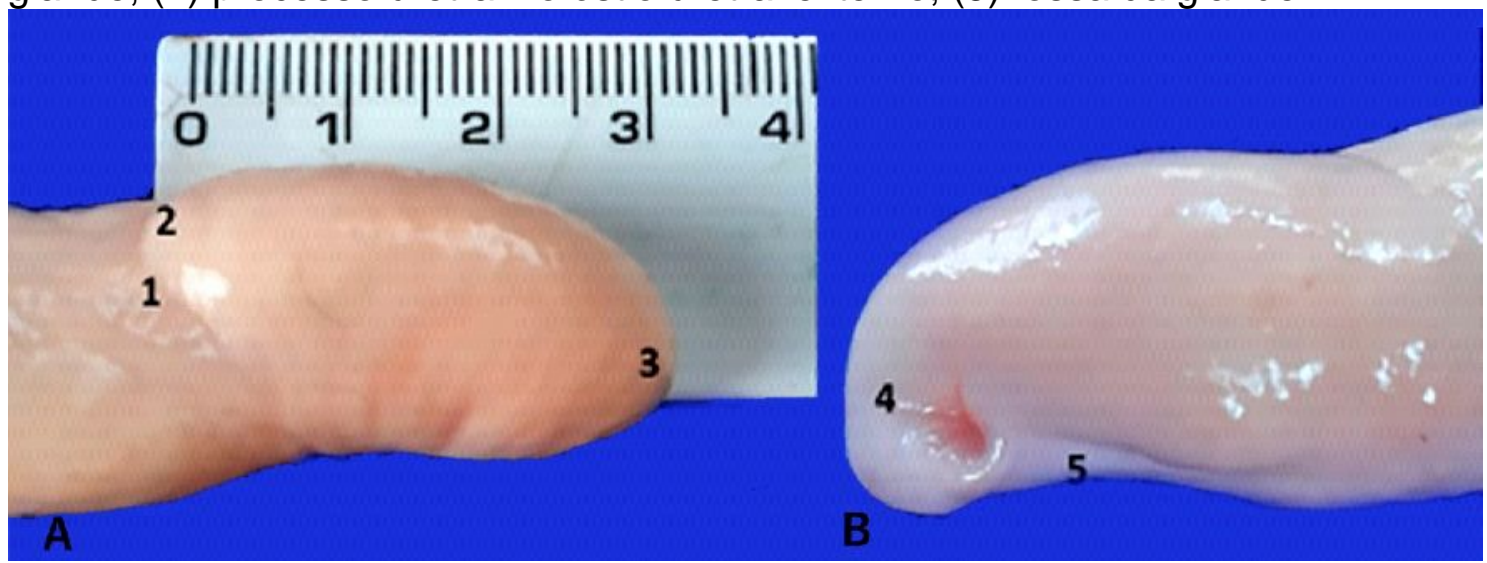

Fonte: Arquivo Pessoal. 
O pênis do ruminante é constituído de tecido fibroelástico, com fibras colágenas que conferem rigidez e resistência, e por fibras elásticas que são maleáveis com boa capacidade de expansão. A túnica albugínea é uma camada espessa de tecido conjuntivo denso, rica em fibras colágenas que envolvem o corpo do pênis. Trabéculas ou septos de tecido fibroso circundam e irradiam-se no interior do corpo cavernoso conferindo relativa rigidez, mas exigindo aporte sanguíneo aos músculos isquiocavernosos durante a ereção do pênis. O corpo esponjoso peniano é recoberto pelo músculo bulboesponjoso, que envolve a uretra peniana inserida dentro do sulco uretral na região ventral do pênis (SCHIMMING; MORAES, 2018).

A flexura sigmoide ou "S" peniano, localizada caudal e dorsalmente ao escroto, é formada por duas curvaturas no corpo do pênis, cuja função é manter o pênis recolhido em repouso dentro do prepúcio. O mecanismo de ereção do touro inicia com estímulos nervosos sensitivos (olfatório, visual e auditivo), que desencadeiam maior fluxo e pressão sanguínea ao pênis, visando preencher os espaços cavernoso e esponjoso e conferir mais rigidez ao pênis fibroelástico. Adicionalmente, o par de músculos retratores do pênis (MRP), desempenha duas funções: quando relaxado desfaz a flexura sigmoide e, consequentemente, o pênis se distende e se projeta alcançando a vulva, durante a cópula; após a cópula, o músculo contrai-se, refazendo a flexura sigmoide e mantendo-a na sua posição normal em repouso sexual (ASHDOWN, 2006).

\section{Morfologia do prepúcio}

O prepúcio ou bainha prepucial é constituído de duas lâminas ou folhetos. $O$ folheto prepucial externo (FPE), formado por uma dobra de pele fina, elástica e móvel, aderida ao ventre do abdômen desde a prega umbilical até a base do escroto (Figura 5). A outra lâmina interna ou folheto prepucial interno (FPI) é a mucosa prepucial. Há citações recentes em que o termo "bainha prepucial" é utilizado como sinônimo de FPE, se referindo à pele externa coberta de pelos, enquanto o termo "prepúcio" refere-se ao FPI. O prepúcio tem como funções importantes proteger a parte livre do pênis e auxiliar no ato da cópula, permitindo que o pênis se projete e alcance a genitália feminina (IRONS, 2020).

O FPE é revestido por epitélio pavimentoso estratificado queratinizado. $\mathrm{Na}$ zona de transição ou interface da pele e mucosa do óstio prepucial estão presentes glândulas sebáceas prepuciais. O óstio prepucial é o orifício ou abertura através do qual ocorre a exteriorização do pênis (Figura 5). Neste órgão ocorre a divisão ou delimitação entre os folhetos, onde ocorre a transição da pele do FPE para mucosa do FPI (EURELL; FRAPPIER, 2012; NABORS; LINFORD, 2015). 
FIGURA 5. Folheto prepucial externo (FPE) ou bainha prepucial e óstio prepucial com presença de pelos de um touro Nelore.

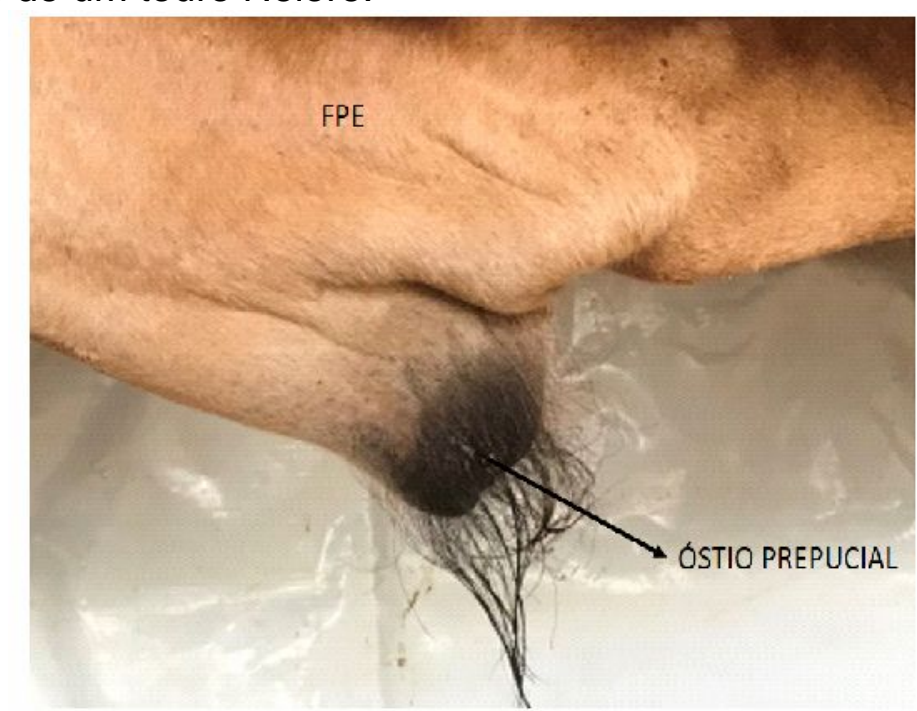

Fonte: Arquivo Pessoal.

Os pelos prepuciais têm como funções a proteção mecânica do óstio e da mucosa prepucial em condições ambientais adversas (agentes causadores de feridas como espinhos e cortes por arame) e também atuam auxiliando na manutenção da mucosa prepucial úmida, evitando o ressecamento. Eventualmente, os pelos prepuciais podem formar feixes densos que podem se prender na mucosa prepucial e ocasionar lesões penianas ou prepuciais (WOLFE, 2018). Akin (2013) relatou um caso raro de anel de pelos prepuciais presos ao redor do pênis em um touro jovem com histórico de discreta hemorragia no óstio prepucial, que ao exame clínico específico foi diagnosticado com um estrangulamento peniano.

A presença de sujidade depende da quantidade e do tamanho dos pelos e da falta de higiene do ambiente (Figura 6). Quanto mais pelos e mais longos, maior a presença de sujidades, crostas, detritos, incrustações, oriundas de restos de matéria orgânica como esterco, e acúmulo de esmegma. Acrescente-se as infestações por carrapatos no prepúcio, principalmente em animais taurinos que são mais acometidos e mais vulneráveis que os zebuínos. Tudo isso pode ocasionar em irritação, lesões prepuciais, e evoluir para afecções mais graves como os abscessos prepuciais e acrobustite. A higienização do prepúcio, mantendo os pelos aparados, diminue as chances de lesões e infecções (WOLFE, 2018). 
FIGURA 6. Touros com variados tamanhos de pelos prepuciais. Em (A) pelos longos e sem sujidade; (B) pelos médios com sujidade; (C) pelos com acúmulo de sujidades.

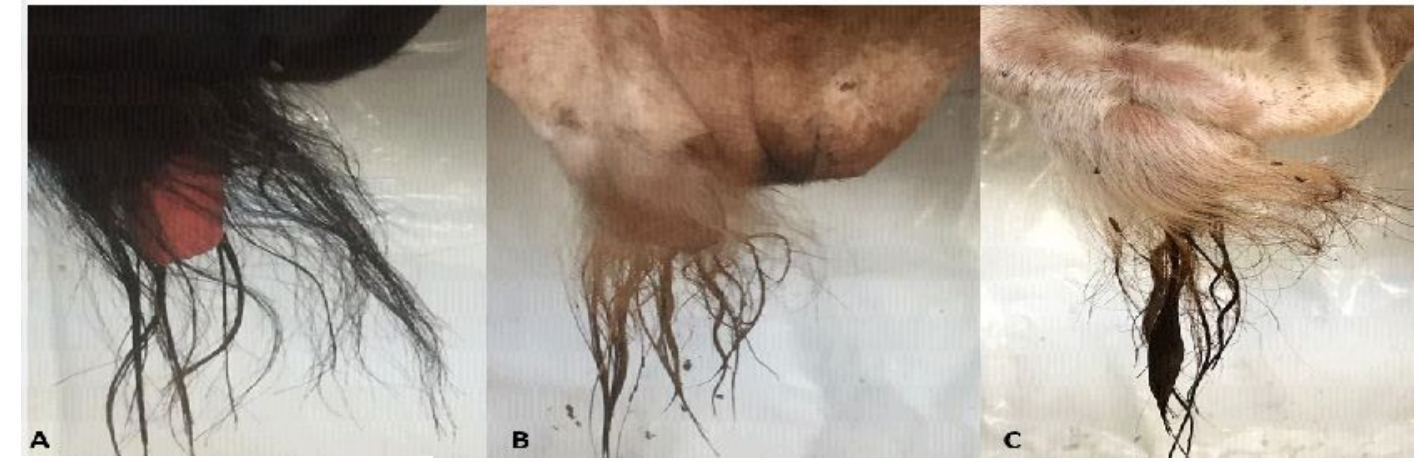

Fonte: Arquivo Pessoal

\section{Medidas e escores de prepúcio}

O tamanho do prepúcio pode ser avaliado por medidas morfométricas (comprimento do prepúcio e distância do óstio ao abdômen) ou por escore visual (TORRES JÚNIOR et al., 2003). Na avaliação visual do prepúcio atribui-lhe escores lineares em escalas que podem variar de 1 a 6 (Figura 7). A nota 1 refere-se a umbigos e bainhas muito reduzidas e a nota 6 corresponde a umbigo e bainha prepucial muito pendulosos. A variação de escores de 2 a 4 é considerada como ideal para a raças zebuínas. Deve-se eliminar do rebanho os touros com prepúcio muito longo, que ultrapasse a linha do jarrete, tendo em vista a herdabilidade dessa característica, a qual predispõe à ocorrência de lesões nessa estrutura (KOURY FILHO et al., 2003; BIGNARDI et al., 2011).

FIGURA 7. Escores de umbigo e de prepúcio de touros Bos taurus indicus.
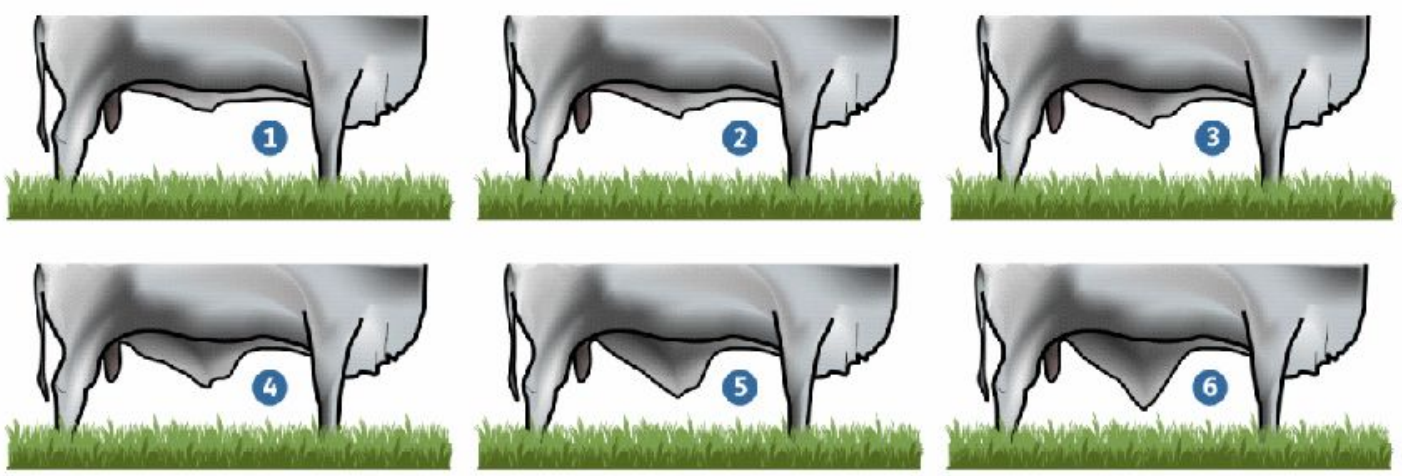

Fonte: Adaptado de Koury Filho et al. (2003).

A morfometria do FPE pode ser realizada com base em três medidas principais (Figura 8): o comprimento do prepúcio, que é a medida da base da bolsa escrotal até o óstio prepucial; a pendulosidade prepucial, que se refere a distância da parede abdominal ventral até o óstio prepucial; e, por fim, o perímetro ou comprimento circular do óstio prepucial (MENDONÇA et al., 2012; HOLGADO et al., 2020). As características morfométricas do prepúcio possuem herdabilidade $\left(h^{2}\right)$ entre 0,20 e 0,30 com resposta 
à seleção, e podem contribuir na prevenção de enfermidades prepuciais e minimizar os prejuízos econômicos aos criadores (VIU et al., 2002).

FIGURA 8. Morfometria do prepúcio de touros. (A) Comprimento do prepúcio; (B) Distância da parede abdominal ao óstio (pendulosidade do prepúcio); (C) Perímetro externo do óstio prepucial.

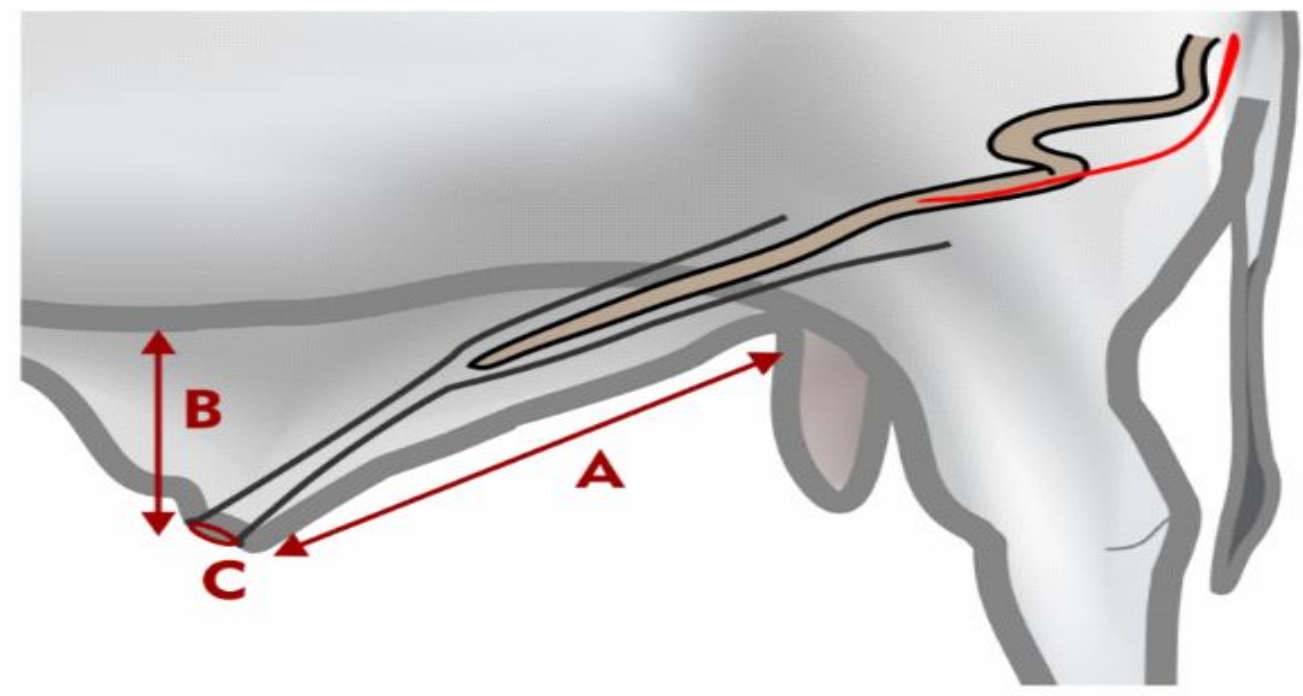

Fonte: Adaptação de Mendonça et al. (2012).

Um estudo sobre a morfometria do prepúcio de touros Nelore e Gir, com 60 a 96 meses de idade, demonstrou que touros Nelore apresentaram FPE com comprimento médio de $52,4 \mathrm{~cm}$, enquanto touros da raça Gir apresentaram FPE com comprimento médio de $57 \mathrm{~cm}$. Neste mesmo estudo, a distância do óstio prepucial à parede abdominal de touros Nelore foi de $20,7 \mathrm{~cm}$, valor menor do que o observado em touros Gir, que foi de $27,9 \mathrm{~cm}$. O perímetro externo do óstio prepucial dos touros Nelore foi de $19,2 \mathrm{~cm}$, enquanto os touros Gir apresentaram perímetro externo de $20,3 \mathrm{~cm}$ (MENDONÇA et al., 2012).

Características anatômicas do sistema genital de machos bubalinos apresentam similaridade com touros bovinos, mas há diferença no tamanho dos órgãos entre estas espécies. Geralmente o pênis do búfalo apresenta comprimento e diâmetro menores. Os búfalos apresentam poucos pelos no óstio prepucial e escruto, assim como em todo o corpo. A bainha prepucial é curta, mais próxima ao abdômen, e se assemelha à encontrada em touros bovinos de origem europeia (HENRY et al., 2017).

\section{Considerações sobre a morfologia do folheto prepucial interno (FPI)}

A constituição histológica do FPI segue o padrão de outras mucosas. A epiderme é revestida por epitélio estratificado pavimentoso. A derme é constituída por camadas de tecido conjuntivo denso elástico e rica rede de vasos sanguíneos. O FPI (Figura 9) tem origem na entrada do óstio prepucial, segue caudalmente como mucosa até o recesso prepucial, para finalmente, voltar-se como uma camada peniana revestindo a superfície do pênis e se inserindo na rafe prepucial. O FPI é um órgão tubular com ENCICLOPÉDIA BIOSFERA, Centro Científico Conhecer - Jandaia-GO, v. 18 n. 37; p. 84 2021 
pregas longitudinais que reveste a cavidade prepucial e aloja a glande e a parte livre do pênis. A cavidade prepucial inicia com a abertura do orifício prepucial, tem aproximadamente $40 \mathrm{~cm}$ de comprimento e três $\mathrm{cm}$ de diâmetro e termina no recesso prepucial (NABORS; LINFORD, 2015).

FIGURA 9. Folheto prepucial interno (FPI) constituído de pregas longitudinais na mucosa. A parte livre do pênis (PLP) incluindo a glande $(G)$ dentro da cavidade prepucial.

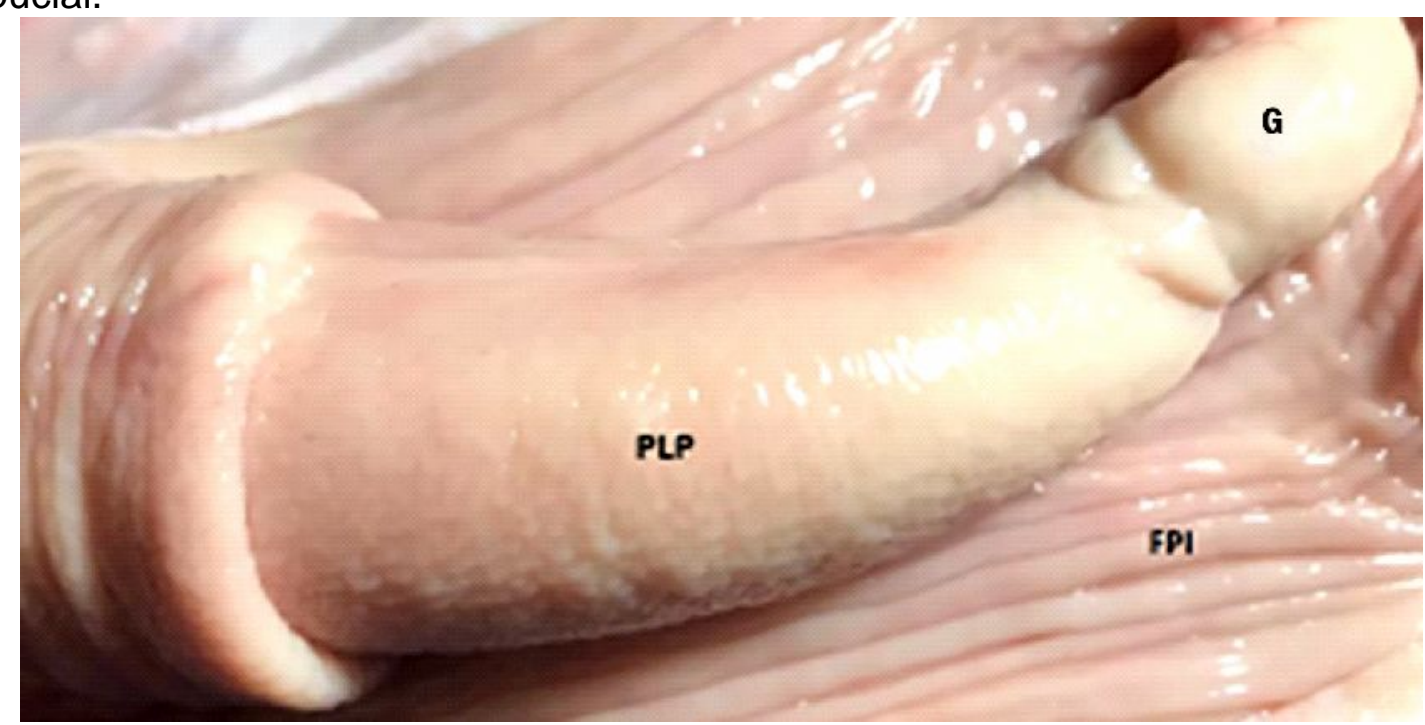

Fonte: Arquivo Pessoal.

O diâmetro e o comprimento do FPI variam consideravelmente entre touros de raças e idades diferentes. O diâmetro prepucial varia de 2 a $4 \mathrm{~cm}$ em raças de Bos taurus taurus e pode exceder este valor em alguns touros de raças Bos taurus índicus. Geralmente, o FPI de um touro adulto mede de 35 a $40 \mathrm{~cm}$ de comprimento, sendo que o FPI de touros Bos taurus índicus mede até $5,5 \mathrm{~cm}$ a mais do que touros de raças Bos taurus taurus (WOLFE, 2018).

Um estudo utilizou o exame ultrassonográfico para avaliar a viabilidade do FPI como critério para a cirurgia corretiva de acropostite-fimose em touros. Os animais que foram submetidos ao procedimento cirúrgico apresentavam no mínimo dois terços do FPI viável, o que resultou em maiores chances de recuperação pós-operatória. Foi recomendado o descarte dos touros que apresentavam comprometimento tecidual envolvendo mais que dois terços do FPI (RABELO et al., 2017b).

Outro estudo teve como objetivo a padronização do exame ultrassonográfico do FPI e da parte livre do pênis (PLP) em bovinos hígidos da raça Nelore. Como conclusão, o exame ultrassonográfico permitiu identificar o FPI e a PLP em todos os planos e em todas as janelas acústicas propostas, sendo que o melhor ponto de referência foi a identificação da glande (SILVA et al., 2020).

Foram verificados: o $\mathrm{pH}$ e a temperatura da cavidade prepucial de 55 touros com idades entre 15 e 84 meses. O resultado da temperatura média do prepúcio foi de $37,81^{\circ} \mathrm{C} \pm 1,76$ e o $\mathrm{pH}$ prepucial médio foi de $8,45(6,35-9,46)$. Houve baixa correlação entre temperatura prepucial com a temperatura ambiental $\left(r_{s}=-0,29\right)$. Touros alimentados com silagem apresentaram pH prepucial médio de 7,6, que foi ENCICLOPÉDIA BIOSFERA, Centro Científico Conhecer - Jandaia-GO, v.18 n.37; p. 85 2021 
significativamente menor do que o de touros alimentados apenas com forragem ou com dietas suplementadas com grãos (8,7 e 8,5, respectivamente). Os autores concluíram que a dieta e a temperatura ambiente podem, respectivamente, afetar o $\mathrm{pH}$ e a temperatura na cavidade prepucial (KOZIOL et al., 2017).

\section{A relação entre aspectos morfológicos do prepúcio e doenças prepuciais}

Existe uma forte relação entre aspectos anatômicos e morfológicos do prepúcio como fatores desencadeantes de enfermidades prepuciais devido à maior exposição aos agentes agressores. Dentre essas afecções, destacam-se as prepuciais (prolapso prepucial, abscesso prepucial, divertículo prepucial, persistência do frênulo prepucial e acropostite-fimose) seguida das penianas (parafimose, desvios, hematomas penianos e fibropapilomatose). Os touros com prepúcio penduloso, orifício prepucial largo e músculos prepuciais ausentes são mais vulneráveis à incidência destas enfermidades, com destaque para a acrobustite-fimose e o prolapso prepucial crônico (CALCIOLARI et al., 2016; HOOPER, 2016; PRADO et al., 2016).

A acrobustite é um processo inflamatório da extremidade do prepúcio, associado a feridas, úlceras, edema, necrose, fibrose, estenose do óstio prepucial, e, consequentemente, fimose e impossibilidade de efetuar a cópula ou Impotência coeundi. A enfermidade é comum em touros de raças zebuínas que realizam monta natural e possuem prepúcio longo, óstio prepucial largo e músculos prepuciais debilitados. Estes animais são vulneráveis a traumatismos prepuciais devido à presença de plantas invasoras, espinhos e arames nos pastos e pela realização de caminhadas forçadas (trote). Em touros de raças taurinas, é comum a ocorrência de lesões no prepúcio ocasionadas por ectoparasitas, resultando em irritação e desenvolvimento de abscessos secundários (SILVA et al., 1994). Além disso, a infecção por Herpesvírus Bovino tipo 1, agente etiológico causador da balanopostite pustular infecciosa, também é apontado como um fator de risco para a gênese de acrobustite (DANTAS et al., 2018).

Outra afecção prepucial relevante é o prolapso prepucial crônico que deve ser diferenciado da eversão prepucial fisiológica. Alguns animais apresentam a eversão prepucial habitual e espontânea do FPI. Esta é uma condição fisiológica, na qual a mucosa do prepúcio se projeta temporariamente para fora do óstio prepucial, mas é recolhida para 0 interior da cavidade prepucial com facilidade e sem impedimento (Figura 10A). Entretanto, a frequente eversão do FPI pode predispor ao ressecamento da mucosa, tornando a mais vulnerável às lesões e evoluir para um caso de prolapso prepucial crônico (Figura 10 B). Essa alteração se caracteriza pela protrusão patológica do prepúcio sem a capacidade de retração espontânea devido ao edema, fibrose e necrose da mucosa prepucial (BODH; BHAT, 2017; VADALIA et al., 2020). 
FIGURA 10. Em (A), touro apresentando a eversão do FPI, que é um processo fisiológico, espontâneo, reversível e temporário. Em (B), touro com prolapso prepucial crônico, que é uma condição patológica que se caracteriza pela mucosa prepucial ressecada, edema, fibrose e necrose.

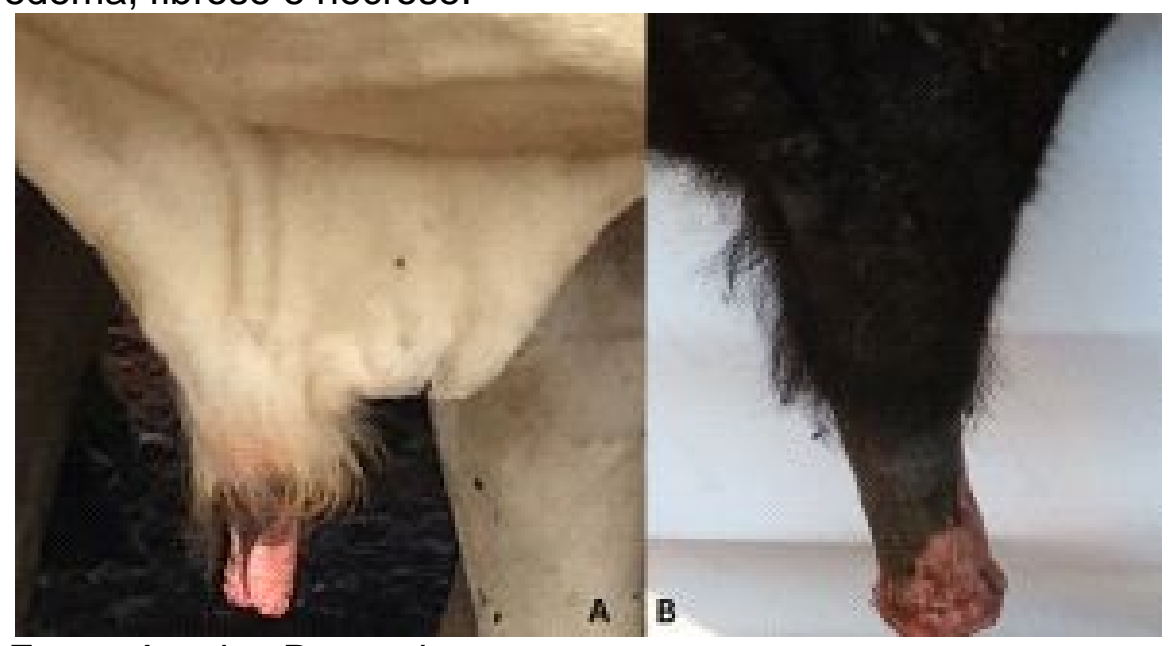

Fonte: Arquivo Pessoal.

Dentro da cavidade prepucial existem microrganismos que são importantes para a homeostase do ambiente prepucial, no entanto desequilíbrios dessa microbiota podem causar doenças. Em situações de trauma ou em condições de imunossupressão, alguns microrganismos patogênicos podem se multiplicar e ocasionar infecções oportunistas (WICKWARE et al., 2020). Quanto maior a idade do touro, mais profundos os sulcos das criptas longitudinais na mucosa prepucial (Figura 11), e maiores são as chance de alojamento e multiplicação de agentes infecciosos de duas doenças venéreas dos bovinos: a tricomoníase genital bovina causada pelo protozoário flagelado Tritrichomonas fetus e a campilobacteriose genital bovina causada pela bactéria Campylobacter fetus venerealis (OYHENART et al., 2018; SILVEIRA et al., 2018).

FIGURA 11. A mucosa do FPI com sulcos longitudinais profundos (setas) favoráveis ao desenvolvimento de patógenos causadores de doenças venéreas.

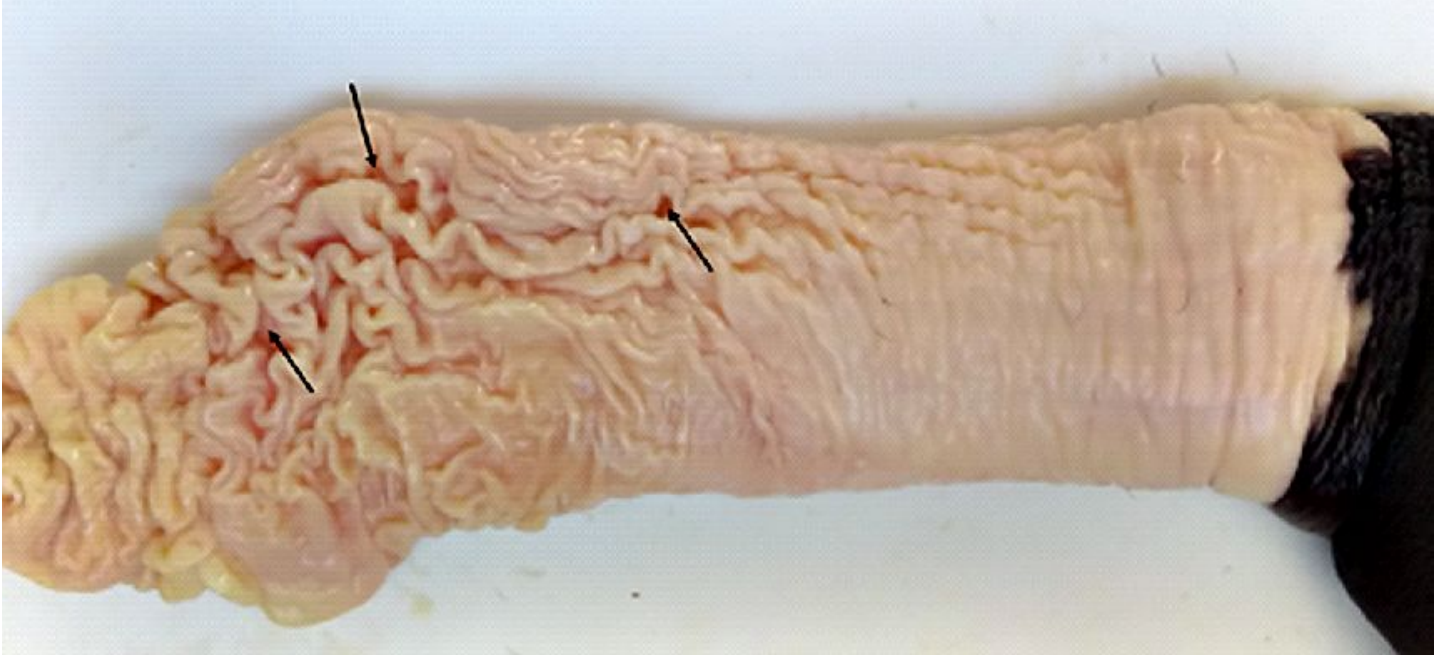

Fonte: Arquivo Pessoal.

ENCICLOPÉDIA BIOSFERA, Centro Científico Conhecer - Jandaia-GO, v.18 n.37; p. 87 


\section{Considerações morfofisiológicas das glândulas sebáceas prepuciais}

As glândulas sebáceas são glândulas exócrinas com apenas um ducto excretor, multicelulares, com unidade secretora circular ou do tipo acinar, preferencialmente do tipo acinar ramificado, com dois ou mais ácinos. São também classificadas como holócrinas, pois as células se rompem ao liberar o conteúdo lipídico e a membrana plasmática, organelas e citoplasma acabam constituindo o produto de secreção (KONIG; LEIBICH, 2011; EURELL; FRAPPIER, 2012).

A função básica da glândula sebácea é a produção de sebo (na pele junto ao folículo piloso) ou esmegma (na pele do óstio prepucial). O sebo é composto essencialmente por lipídios triglicerídeos, ácidos graxos, ésteres de cera, ésteres de colesterol e colesterol. Os lipídios sebáceos constituem a maior parte dos lipídios da superfície da pele. O sebo tem a função de lubrificar a pele, evitar o ressecamento, controlar a perda de água, atuar como antioxidante, efetuar atividade antibacteriana e promover a síntese de feromônios nos animais (SMITH; THIBOUTOT, 2008).

Além das funções primárias e específicas relacionadas com a homeostase da pele, pesquisas recentes afirmam que as glândulas sebáceas podem contribuir com o metabolismo de lipídios exercendo ação lipogênica, hormonal e imunológica. Como exemplo, o colesterol, que é um constituinte do sebo, é precursor do hormônio andrógeno e importante para a síntese de vitamina E. Além disso, os sebócitos são capazes de produzir mediadores inflamatórios ou citocinas, que são interleucinas e fator de necrose tumoral (SZOLLOSI et al., 2017).

Os fatores que afetam a fisiologia das glândulas sebáceas são os estímulos hormonais intrínsecos ao animal (sexo, idade e raça) e fatores ambientais ou climáticos. A quantidade e o volume de glândulas sebácias podem variar entre as espécies, raças e regiões do corpo. O principal estímulo para a produção de sebo é a ação hormonal de andrógenos, principalmente, na puberdade. Os sebócitos tornam-se ativos mediante ação de testosterona. Além disso, essas células possuem receptores para outros hormônios, principalmente, o hormônio liberador de corticotropina $(\mathrm{CRH})$ e o hormônio de crescimento $(\mathrm{GH})$, através do fator de crescimento epidérmico (EGF) que é um hormônio de crescimento específico da pele (SZOLLOSI et al., 2017).

A pele do macho tem mais glândulas sebáceas e a produção de sebo é maior e mais oleosa do que nas fêmeas. A glândula sebácea é um órgão-alvo para andrógenos, mas também é capaz de sintetizar testosterona e de converter essa testosterona em $5 \alpha$-dihidrotestosterona ( $5 \alpha-\mathrm{DHT})$. A orquiectomia ou castração provoca a diminuição da atividade das glândulas sebáceas. Por outro lado, aplicação de testosterona exógena em um animal submetido à castração promove aumento na atividade glandular. Na prépúberdade, as glândulas são imaturas e, em animais senis, as glândulas diminuem a capacidade de produzir lipídios, ou seja, a quantidade de glândulas tende a diminuir com o aumento da idade, ocorrendo menor lubrificação da pele e dos pelos (HOOVER et al., 2020).

As glândulas sebáceas não apresentam relação direta com as glândulas sudoríparas na termorregulação do corpo. No entanto, a atividade de produção de sebo pode ser influenciada pela temperatura da pele dos animais. Temperaturas baixas podem reduzir a secreção das glândulas sebáceas e ocasionar o ressecamento da pele e pelos. Na estação do verão, há maior atividade das glândulas sebáceas da pele do que no inverno. Em clima tropical, as glândulas sebáceas demonstram maior capacidade secretória, o que evita o ressecamento da camada superficial da pele e ENCICLOPÉDIA BIOSFERA, Centro Científico Conhecer - Jandaia-GO, v.18 n.37; p. 88 2021 
promove maior reflexão da radiação solar e, consequentemente, maior proteção dos efeitos deletérios desta radiação (COSTA et al., 2020).

$\mathrm{Na}$ espécie bovina, há poucos estudos sobre as glândulas sebáceas da superfície da pele. Não foi encontrado nenhum estudo específico sobre as glândulas sebáceas prepuciais em touros. Geralmente, as informações são descritas nos livros de histologia veterinária (EURELL; FRAPPIER, 2012).

\section{Esmegma}

O esmegma é uma secreção produzida pelas glândulas sebáceas prepuciais e é constituída de restos de células de descamação e lipídios. Essa secreção tem a função de umedecer, lubrificar, evitar o ressecamento da mucosa e auxiliar na introdução do pênis na genitália feminina. Além disso, essa substância apresenta atividade antimicrobiana e contêm feromônios sexuais com propriedades odoríferas (RABELO et al., 2012).

Todavia, o esmegma parece apresentar uma função paradoxal ao FPI. Alguns autores sugerem que esta substância lipídica atua como fator desencadeante do carcinoma espinocelular genital em equinos machos e castrados, porque nestes, o acúmulo da secreção é maior do que nos garanhões. Porém, ainda não foi esclarecido se o desenvolvimento do tumor está relacionado a uma irritação crônica ou a substâncias carcinogênicas do esmegma (RAMALHO et al., 2018).

Em bovinos, o esmegma atua como um meio de cultura para o desenvolvimento de doenças venéreas. Acrescente-se que as pregas longitudinais da mucosa prepucial facilitam a colonização de agentes contagiosos responsáveis por doenças sexualmente transmissíveis, tais como, a tricomoníase e campilobacteriose (OYHENART, 2018; SILVEIRA et al., 2018; BALZAN et al., 2020).

Em humanos, existe uma relação entre a circuncisão e higiene prepucial no controle do acúmulo excessivo de esmegma e a prevenção de enfermidades da genitália e doenças sexualmente transmissíveis (DST). Homens circuncidados na infância apresentam menor risco de desenvolverem carcinoma peniano e contribuem para uma menor taxa de câncer do colo do útero de suas parceiras. No entanto, se a essência da circuncisão é promover a higiene, pode-se concluir que a limpeza diária do prepúcio provavelmente alcançará benefício semelhante à circuncisão. No entanto, são necessários estudos adicionais para avaliar os benefícios da higiene prepucial na substituição da prática da circuncisão ou efeito aditivo de ambas as medidas (BAILIS et al., 2019; MORRIS et al., 2019).

\section{CONSIDERAÇÕES FINAIS}

Esta revisão permitiu realçar aspectos morfológicos da genitália externa de touros que poderão servir como base para estudos de parâmetros morfométricos do prepúcio de bovinos e auxiliar na seleção de reprodutores, tanto para fins de melhoramento de características morfológicas, quanto para a prevenção de enfermidades prepuciais. Recomenda-se a eliminação de touros que apresentam prepúcio longo, tendo em vista a herdabilidade genética desta característica e a predisposição a traumatismos prepuciais.

Acrescente-se a importância de estudos adicionais sobre as glândulas sebáceas prepuciais, para aprofundar os conhecimentos sobre a função do esmegma e as 
condições nas quais essa substância pode estar associada à lesões prepuciais e penianas.

\section{REFERÊNCIAS}

AKIN, I. A case of penile hair ring in a young bull. Animal Health, Production and Hygiene, v. 2, n. 2, p. 212-213, 2013. Disponível em: <https://dergipark.org.tr/en/download/issue-file/36096>.

ASHDOWN, R. R. Functional, developmental and clinical anatomy of the bovine penis and prepuce. CABI Reviews Perspectives in Agriculture, Veterinary Science, Nutrition and Natural Resources, v. 1, n. 21, p. 29-37, 2006. Disponível em: $<$ https://www.researchgate.net/publication/240511659

Functional developmental_and_clinical_anatomy_of_the_bovine_penis_and_prepuce>. doi: 10.1079/PAVSNNRR20061021

BAILIS, S. A.; MORETON, S.; MORRIS, B. J. Critical evaluation of a survey claiming "long-term adverse outcomes from neonatal circumcision". Scientific Research Publishing. Advances in Sexual Medicine, v. 9, p. 67-109, 2019. Disponível em: $<$ https://www.researchgate.net/publication/335850471_Critical_Evaluation_of_a_Survey Claiming_Long-Term_Adverse_Outcomes_from_Neonatal_Circumcision>. doi: 10.4236/asm.2019.94006

BALZAN, C.; ZIECH, R. E.; GRESSLER, L. T.; VARGAS, A. P. C. Bovine genital campylobacteriosis: main features and perspectives for diagnosis and control. Ciência Rural, v. 50, n. 3, p. 1-9, 2020. Disponível em: <https://doi.org/10.1590/01038478cr20190272>. doi: 10.1590/0103-8478cr20190272

BARUSELLI, P. S.; CATUSSI, B. L.C.; ABREU, L. A.; ELLIFF, F. M.; SILVA, L. G. et al. Evolution and perspectives of timed artificial insemination in cattle. Revista Brasileira de Reprodução Animal, v. 43, n. 2, p. 308-314, 2019. Disponível em: <http://repositorio.ufla.br/jspui/handle/1/38655>.

BIGNARDI, A. B.; GORDO, D. G. M.; ALBUQUERQUE, L. G.; SESANA, J. C. Parâmetros genéticos de escore visual do umbigo em bovinos da raça Nelore. Arquivo Brasileiro de Medicina Veterinária e Zootecnia, v, 63, n. 4, p. 941-947, 2011. Disponível em: <https://doi.org/10.1590/S0102-09352011000400020>. doi: 10.1590/S0102-09352011000400020

BODH, D.; BHAT, S. A. I. Surgical management of chronic preputial prolapse in a bull. Intas Polivet, v. 18, n. 2, p. 404-406, 2017.

BUDRAS, K. D.; HABEL, R. E. Bovine anatomy. 6. ed. Hannover, Germany: Schluetersche, 2003. $140 \mathrm{p}$.

CALCIOLARI, K.; BARROCO, V.; GRAVENA, K.; CANOLLA, P. A. Principais doenças prepuciais e penianas em bovinos. Revista Investigação, v. 15, p. 83-90, 2016. 
Disponível em: <https://doi.org/10.26843/investigacao.v15i4.1388>. doi: 10.26843/investigacao.v15i4.1388

COSTA, J. H. S.; FURTADO, D. A.; LOPES NETO, J. A.; RIBEIRO, N. L.; DAMACENO, L. F. S. et al. Conforto térmico e estrutura tegumentar de ovinos mantidos em ambiente coberto e descoberto. Brazilian Journal of Development, v. 6, n. 4, p. 20449-20461, 2020. Disponível em: <https://doi.org/10.34117/bjdv6n4-281>. doi: 10.34117/bjdv6n4281

DANTAS, G. C.; GASPARIN, A. L.; PEREIRA, J. F.S.; WELINGTON, H. Balanopostite em bovinos: Relato de caso. Revista Eletrônica Biociências, Biotecnologia e Saúde, v. $11, \quad$ n. 22, p. 24-33, 2018. Disponível em: <https://interin.utp.br/index.php/GR1/article/view/2265/1887>.

DESROCHERS, A.; SAINT-JEAN, G.; ANDERSON, D. E. Surgical management of preputial injuries in bulls: 51 cases (1986-1994). Canadian Veterinary Journal, v. 36, n. 9, p. 553-556, 1995. Disponível em: <https://pubmed.ncbi.nlm.nih.gov/ 7497424/>. doi: 10.1111/avj. 12650

DYCE, K. M.; SACK, W. O.; WENSING, C. J. G. Tratado de anatomia veterinária. 2. ed. Rio de Janeiro: Guanabara Koogan, 1997, 663 p.

EURELL, J. Á.; FRAPPIER, B. L. Histologia Veterinária Delmann. 6. ed. São Paulo: Manole, 2012. 400 p.

EURIDES, D. SILVA, L. A. F.; FIORAVANTI, M. C. S.; CHAVES, N. S.T.; CAMPOS, V. A. et al. Aspectos morfológicos e morfométricos do ligamento apical do pênis de bovinos da raça Nelore. ARS Veterinária, v. 14, n. 2, p. 116-128, 1998.

HAFEZ, E. S. S. E.; HAFEZ, B. Reprodução animal. 7. ed. Baruei: Manole, 2004. 513 p.

HENRY, M.; BRITO, M. F.; NEVES, B. P.; AULER, P. A.; ALMEIDA, J. et al. Exame andrológico de bubalinos. Revista Brasileira de Reprodução Animal, v. 41, n. 1, p. 188-194, 2017. Disponível em: <http://webcache.googleusercontent.com/search?q=cache:m3sAqedqi8UJ:www.cbra.or g.br/portal/downloads/publicacoes/rbra/v41/n1/p188-194\%2520(RB655).pdf+ $\& c d=2 \& h l=p t-B R \& c t=c \mid n k \& g l=b r>$.

HOLGADO, F. D.; RABASA, A. E.; ORTEGA, M. F.; MARTINEZ, R. E. Longitud de prepucio en la raza bovina criollo argentino. Actas Iberoamericanas de Conservación Animal, v. 64, n. 14, p. 69-72, 2020. Disponível em: <https://webcache.googleusercontent.com/search?q=cache:

C5SKvxQBXpkJ:https://aicarevista.jimdo.com/app/download/18349706325/AICA_Vol14 Trabajo014.pdf\%3Ft\%3D1580214720\%26mobile\%3D1+\&cd=1\&hl=pt-

$\overline{B R} \& c t=c l n k \& g l=b r>$. 
HOOVER, E.; ASLAM, S.; KRISHNAMURTHY, K. Physiology, sebaceous glands. Treasure Island: StatPearls Publishing, 2020. Disponível em: <https://pubmed.ncbi.nlm.nih.gov/29762994/>.

HOPPER, R. M. Management of male reproductive tract injuries and disease. The Veterinary Clinics of North America. Food Animal Practice, v. 32, n. 2, p. 497-510, 2016. Disponível em: <https://pubmed.ncbi.nlm.nih.gov/27039689/>. doi: 10.1016/j.cvfa.2016.01.015

IRONS, P. C. Applied anatomy, pathophysiology and a revised scoring system of bull sheaths. Australian Veterinary Journal, v. 98, n. 1-2, p. 48-52, 2020. Disponível em: <https://doi.org/10.1111/avj.12900>. doi: 10.1111/avj.12900

KONIG, H. E.; LEIBICH, H. G. Anatomia dos animais domésticos. 3. ed. Porto Alegre: Artmed, $2011.787 \mathrm{p}$.

KOURY FILHO, W. JUBILEU, J.S.; ELER, J.P. Parâmetros genéticos para escores de umbigo e características de produção em bovinos da raça Nelore. Arquivo Brasileiro de Medicina Veterinária e Zootecnia, v. 55, n. 5, p. 594-598, 2003. Disponível em: <https://doi.org/10.1590/S0102-09352003000500013>. doi: 10.1590/S010209352003000500013

KOZIOL, J. H.; JUBILEU, J. S.; ELER, J. P.; FERRAZ, J. B. S.; PEREIRA, E. et al. Initial steps in defining the environment of the prepuce of the bull by measuring $\mathrm{pH}$ and temperature. Australian Veterinary Journal, v. 95, n. 12, p. 480-482, 2017. Disponível em: <https://pubmed.ncbi.nlm.nih.gov/29243240/>.

McGOWAN, M.; HOLLAND, M. K.; BOE-HANSEN, G. Review: Ontology and endocrinology of the reproductive system of bulls from fetus to maturity. Animal, v. 12, n. 1, p. 19-26, 2018. Disponível em: <https://pubmed.ncbi.nlm.nih.gov/29551096/>. doi: $10.1017 / \mathrm{S} 1751731118000460$

MENDONÇA, A. C.; CARDOSO, J. R.; MOREIRA, P. C.; JUNQUEIRA, D. D.; MENDONÇA, F. P. X. et al. Morphometric characterization of the penis and prepuce of nelore and gir bulls. Bioscience Journal, v. 25, n. 6, p. 985-992, 2012. Disponível em: $<$ https://www.researchgate.net/publication/ 287042797_Morphometric characterization_of_the_penis_and_prepuce_of_nelore_and_Gir_bulls>.

MENDONÇA, K. A.; FIGUEIREDO, J. R.; MELO, S. L.; SILVA, M. C.; CRUZ, D. M. et al. Importância dos aspectos biométricos na seleção de reprodutores bovinos: Revisão. Pubvet, v. 13, n. 12, p. 1-8, 2019. Disponível em: <https://doi.org/10.31533/pubvet.v13n12a475.1-8>. doi: 10.31533/pubvet.v13n12a475.1-8

MORRIS, B. J.; HANKINS, C. A.; BANERJEE, J.; LUMBERS, E. R.; MINDEL, A. et al. Does male circumcision reduce women's risk of sexually transmitted infections, cervical cancer, and associated conditions? Frontiers In Public Health, v. 7, p. 1-8, 2019. ENCICLOPÉDIA BIOSFERA, Centro Científico Conhecer - Jandaia-GO, v. 18 n. 37 ; p. 92 
Disponível em: <https://www.ncbi.nlm.nih.gov/pmc/articles/PMC6365441/>. doi: 10.3389/fpubh.2019.00004

NABORS, B.; LINFORD, R. Anatomy of the reproductive system of the bull. In: HOPPER, R. M. (Ed.). Bovine reproduction. Ames: Jonh Wiley \& Sons, 2015. p. 5-10.

OYHENART, J. Direct detection of Tritrichomonas foetus in cattle genital fluid trough loop mediated isothermal amplification of elongation factor 1 alpha 1 . Veterinary Parasitology, v. 261, p. 67-72, 2018. Disponível em: <https://doi.org/10.1016/j.vetpar.2018.08.011>. doi: 10.1016/j.vetpar.2018.08.011

PRADO, T. M.; DAWSON, L. J.; SCHUMACHER, J. Surgical procedures of the genital organs of bulls. The Veterinary clinics of North America. Food Animal Practice, v. 32, n. 3, p. 701-725, 2016. Disponível em: <https://pubmed.ncbi. nlm.nih.gov/27719767/>. doi: 10.1016/j.cvfa.2016.05.016

RABELO, R. E.; VULCANI, V. A. S.; CARDOSO, L. D.; DUTRA, H. T.; HELRIGEL, P. A. et al. Aspectos anatômicos e sua relação com as enfermidades do prepúcio e pênis no touro. Revista Científica Eletrônica de Medicina Veterinária, v. 9, n. 18, p. 1-30, 2012. Disponível em: <http://faef.revista.inf.br/imagens_ arquivos/arquivos_destaque/atYEslptZwuCRI8_2013-6-25-18-3-59.pdf>.

RABELO, R. E.; SILVA, L. A. F.; SILVA, O. C.; VULCANI, V. A. S. Cirurgias do aparelho reprodutor de machos bovinos e equinos. São Paulo: MedVet, 2017a. 292 p.

RABELO, R. E.; SILVA. L. A. F.; VULCANI, V. A. S.; SANT'ANA, F. J. F.; ASSIS, B. M. et al. Enfermidades diagnosticadas na genitália externa de touros: Estudo retrospectivo (2007-2013). Ciência Animal Brasileira, v. 16, n. 1, p. 133-143, 2015. Disponível em: <https://doi.org/10.1590/1089-68916i130990>. doi: 10.1590/1089-68916i130990

RABELO, R. E.; SILVA, L. A. F.; BRITO, L. A. B.; MOURA, M. I.; SILVA, O. C. et al. Epidemiological aspects of surgical diseases of the genital tract in a population of 12,320 breeding bulls (1982-2007) in the state of Goias, Brazil. Ciência Animal Brasileira, v. 9, n. 3, p. 705-713, 2008. Disponível em: <https://www.revistas.ufg.br/vet/article/view/1199/4141>.

RABELO, R. E.; SILVA, L. A. F.; BORGES, N.C.; VULCANI, V. A. S.; OLIVEIRA, R. S. et al. Novas perspectivas no diagnóstico e tratamento da acropostite-fimose em touros. Arquivo Brasileiro de Medicina Veterinária e Zootecnia, v. 69, n. 4, p. 851 859, 2017b. Disponível em: <https://doi.org/10.1590/1678-4162-9239>. doi: $10.1590 / 1678-4162-9239$

RAMALHO, L. N.; OPORTO, C. I. S.; YAMADA, D. I.; SILVA, G. L. G.; MANZAN, I. B. et al. Penectomia parcial em equino com carcinoma espinocelular: relato de caso. Revista de Educação Continuada em Medicina Veterinária e Zootecnia do CRMV-SP, v. 16, 
n. 3, p. 60-68, 2018. Disponível em: <https://doi.org/10.36440/recmvz.v16i3.37820>. doi: $10.36440 /$ recmvz.v16i3.37820

SCHALLER, O. Nomenclatura anatômica veterinária. São Paulo: Manole, 2017. 614 p.

SCHIMMING, B. C.; MORAES, G. N. Morphological analysis of the elastic and collagen fibers in the ram penis. Pesquisa Veterinária Brasileira, v. 38, n. 11, p. 2159-2165, 2018. Disponível em: <https://www.scielo.br/j/pvb/a/ 5wcRY3bGXcWRTTdcVp3rVdx/?format=pdf\&lang=en>.doi: $\quad$ 10.1590/1678-5150-pvb5325

SILVA, L. A. F.; FIORAVANTI, M. C. S.; BORGES, N. C.; CARNEIRO, M. I.; SILVA, C. A. Utilização do avental como auxiliar no pós-operatório da acrobustite ou acrobustitefimose. Anais da escola de Agronomia e Veterinária, v. 24, n. 1, p. 142-147, 1994. Disponível em: <https://www.revistas.ufg.br/pat/article/ view/2674>. doi: 10.5216/pat.v24i1.2674

SILVA, N. A. A.; SILVA, L. A. F.; LIMA, V. H.; CUNHA, P. H. J.; CARDOSO, J. R. et al. Padronização do exame ultrassonográfico do prepúcio e da parte livre do pênis em bovinos. Arquivo Brasileiro Medicina Veterinária e Zootecnia, v. 72, n. 1, p. 40-48, 2020. Disponível em: <https://doi.org/10.1590/1678-4162-10983>. doi: 10.1590/16784162-10983

SILVEIRA, C. S.; FRAGA, M.; GIANNITTI, F.; MACÍAS-RIOSECO, M.; RIET-CORREA, $F$. Diagnosis of bovine genital campylobacteriosis in South America. Frontiers in Veterinary Science, v. 5, p. 1-9, 2018. Disponível em: <https://www.ncbi.nlm.nih.gov/pmc/articles/PMC6302017/>. doi: 10.3389/fvets.2018.00321

SMITH, K. R.; THIBOUTOT, D. M. Thematic review series: skin lipids. Sebaceous gland lipids: friend or foe? Journal of Lipid Research, v. 49, n. 2, p. 271-281, 2008. Disponível em: <https://pubmed.ncbi.nlm.nih.gov/17975220/>. doi: 10.1194/jlr.R700015JLR200

SZÖLL SI, A. G.; OLÁH, A.; BÍRÓ, T.; TÓTH, B. I. Recent advances in the endocrinology of the sebaceous gland. Dermato-Endocrinology, v. 9, n. 1, p.19381948, 2017. Disponível em: <https://pubmed.ncbi.nlm.nih.gov/29484098/>. doi: 10.1080/19381980.2017.1361576

TORRES JÚNIOR, R. A. A.; BIGNARDI, A. B.; SILVA, L. O. C. Seleção para correção de prepúcio e ausência de prolapso em touros de corte. Campo Grande: EMBRAPA-CNPGC, 2003. 22 p. (Documentos, 137).

VADALIA, J. V.; TANK, P. H.; DODIA, V. D.; TALEKAR, S. H.; PADALIYA, N. R. et al. Clinical survey on preputial prolapse in gir bulls. Indian Journal of Veterinary Sciences and Biotechnology, v. 15, n. 3, p. 66-68, 2020. Disponível em: 
$<$ https://www.researchgate.net/publication/348071894_Clinical_

Survey_on_Preputial_Prolapse_in_Gir_Bulls>.doi: 10.21887/ijvsbt.15.3.17

VIU, M. A. O.; TONHATI, T. I.; CERÓN-MUNHÕZ, M. F.; FRIEZ, L. A.; TEIXEIRA, R. A. Parâmetros genéticos do peso e escores visuais de prepúcio e umbigo em gado de corte. ARS Veterinária, v. 18, n. 2, p.179-184, 2002. Disponível em: $<$ https://www.researchgate.net/publication/ 273141109_Parametros_geneticos do_peso_e_escores_visuais_de_prepusio_e_umbigo_em_gado_de_corte>.

WICKWARE, C. L.; JOHNSON, T. A.; KOZIOL, J. H. Composition and diversity of the preputial microbiota in healthy bulls. Theriogenology, v. 145, p. 231-237, 2020. Disponível em: <https://pubmed.ncbi.nlm.nih.gov/31732161/>. doi: 10.1016/j.theriogenology.2019.11.002

WOLFE, D. F. Review: Abnormalities of the bull - occurrence, diagnosis and treatment of abnormalities of the bull, including structural soundness. Animal, v. 12, n. 1, p. 148157, 2018. Disponível em: <https://pubmed.ncbi.nlm.nih.gov/ 29717682/>. doi: $10.1017 / \mathrm{S} 1751731118000939$ 